\title{
RETRACTED ARTICLE: Characterization of atmospheric optical turbulence by (GDIMM) telescope
}

\author{
Sabah Al-ithawi ${ }^{1}$ (D)
}

Received: 27 June 2017/ Accepted: 18 October 2017/Published online: 4 November 2017

(C) The Optical Society of India 2017

The Editor has retracted this article [1], because the author did not have the ownership of the data reported. This was confirmed by an investigation by University of Nice Sophia Antipolis. The Author did not agree to this retraction.
The online version of this article contains the full text of the retracted article as electronic supplementary material.

[1] Al-ithawi, S. Characterization of atmospheric optical turbulence by (GDIMM) telescope. J Opt (2017). https:// doi.org/10.1007/s12596-017-0431-0

Electronic supplementary material The online version of this article (https://doi.org/10.1007/s12596-017-0431-0) contains supplementary material, which is available to authorized users.

\section{Sabah Al-ithawi}

sa_laser@yahoo.com

1 Department of Laser and Optoelectronic Engineering,

University of Technology, Baghdad, Iraq 